\title{
BIJDRAGEN TOT DE OUD-JAVAANSCHE LEXICOGRAPHIE.
}

\author{
DOOR
}

Dr. J. GONDA.

\section{Woorden, voorkomende in de Calon-Arang.}

Een tweede geschrift, waarvan de lexicographische bijzonderheden niet volledig in de Woordenlijst van Dr. H. H. Juynboll zijn opgenomen, is de Calon-Arang, in 1926 door Dr. Poerbatjaraka in de Bijdragen gepubliceerd (deel 82, pp. 110-180). Daar de uitgever, evenals Dr. Pigeaud bij de Tantu Panggělaran, bij de editie een vertaling gevoegd heeft, is de hier volgende woordenlijst niet in de eerste plaats bedoeld om het lezen van den tekst te vergemakkelijken, doch eerder om de woorden die om de een of andere reden merkwaardig zijn, te verzamelen. Weliswaar geeft Van der Tuuk's Kawi-Balineesch Woordenboek er vele van, doch deze zijn in de editie niet terug te vinden; in Juynboll's Woordenlijst is slechts een zeer klein gedeelte kunnen worden opgenomen. De keuze is in onderstaande verzameling zeer ruim gehouden, evenals bij mijn onlangs gepubliceerd glossarium op de Tantu Panggělaran.

De afkortingen zijn dezelfde, slechts:

$$
\text { Poerb. }=\text { Dr. Poerbatjaraka. }
$$

uhut, inuhutakĕn, 130, 135, ,,vertellen van” (Poerb.), e.a. iets uiteenzetten, onderrichten in iets. -, umuhuta, 130; umuhutakěn, 131, 134.

andika, mandika, 123, 137, spreken (van den vorst). Zie ook p. 135, $139,142$.

intih, angintih-intih, 127, zachtjes snikken (Poerb.).

hčrit, ahrit, 136, on veilig (van wegen enz.). Verg. Soend. hĕrit, id. haryi, 144, voeten; haryan, 140, voeten (Poerb.); K. B. W. I, 122.

čkas, 144 , = wĕkas.

ad $\breve{g}$, pangaděg, 135, „stel” (kleeren), als N. J.

atur, ature, 128. 
atithi, S., pātithen, palangka p., 124.

hosi, ahosyan, 120, in rustelooze beweging zijn. Zoo ook Răm. 17,

82 ; B. Y. 31, 23; de opgave van Jb., p. 678, is niet juist.

isar, ingisar; kesar, 134, dompelen (?).

azuani, pakāwaniya, 139, m.i. af te leiden van Skt. avanī, behoedend, bij avana, redder (zie Schmidt, Nachträge, s.v.); behoeder > vorst.

awyatara, 125, = awatara, zie: watara.

ělah (?), pangělahan, 117, kerkhof.

ular, kolaran, 117, 127, 128, vgl. N. J. ngoelari, ngoelati, bezien, bekijken, aanzien.

ělek, mangĕlekakĕn, 121, als N. J. (de oogen openen).

eled, meled $^{2}, 121$, vgl. N. J. elet, het uitsteken van de tong.

ilag, umilag, 132, vertrekken.

hulěng, humulĕng, 119, iem. in 't haar grijpen.

ijig, ngijig-ijig, 121, ? K. B. W. I, 338. N. J. ijig, ejeg, trippelgang. uyahharĕng, moyahharěngan, 133, van uyah + arĕng, verg. K. B. W. I, 129. Vgl. 144.

ayun, 129, (ing - : vóór). - , mangayunakěn, $125,=$ N. J. ngarěpake, dicht aan toe zijn.

homa, angomani, 133, d.i. anghomani, inwijden, inzegenen (met een offer).

ampihan, 142, $143(3 \times)$, (afgegrensd) gebied.

imba, unimba, 131, leze: um-; mimba: mijil, zie K. B. W. IV, 610. aghani, 141, = koning (Poerb.).

angçoka, 118, = açoka ('n boom).

nittiyogya, 117, 129, 134, e.a., ,wat dienstig is voor goed gedrag”. nastāpa, 144. Skt. manastāpa. Zie onder: duhkha.

nawaratna, 135, 141, 145, de negen juweelen: koraal, parel, enz. (Zie

Pet. Wdb., s.v.).

namu, namu-namu, 123, 145; vgl. K. B. W. I, 553 en Jb., s.v.

nibrata, 141, 142, (zie ook p. 142, 24), gezegd van mpu Bharada, \pm ,heilige”. Etym.: Skt. ? Samenhang met vrata, of soms een verbastering van nibhrta, onbewegelijk, zich stil houdend; trouw, aanhankelijk; bescheiden; ongemerkt? Zeer onzeker.

cina, 118, zekere plant; vgl, Poerb., p. 149.

corok, silih corokana, 143. Zie K. B. W. I, 592; overeenkomstig het

N. J. gebruik.

cidra, - pateni, 119; cumidra, 119, (arglistig) vermoorden.

caḍang, cumaḍang, 141, gereed, present, zijn. 
reh, i rehan i, 123 door de omstandigheid, dat; omdat. Vgl. 127, 130, 136: i rehan ika.

rihin, karihin, 124, 125, 131, 132; vgl. dihin, bv. 128.

rěntěp, rwanya marĕntěp, 120. Zie K. B. W. onder rĕntĕb, I, 705. rěke, $124 ; \mathrm{K} . \mathrm{B} . \mathrm{W}$. I, 722.

rata, mangrata ${ }^{2}$, 118, gelijk, effen, maken. Zie Bijdr. 89, p. 80.

rasun, 125 , ik.

rwa, karwa, angarwani, 132, iemand helpen, bijstaan.

rawĕh, $140,=$ rawuh, aankomen (hier van uit de lucht).

rawuh, 127, 129, aankomen. Vgl. Nāg. 90, 1, 4.

rěmbe, -um-, 120.

rĕmběn, angr ${ }^{\circ}, 127$, bladerrijk, welig groeiend. Vgl. K. W. B. I, $798 ; 417$.

rambang, angrambang, 136, advies vragen (Poerb.). Men gevoelt zich

herinnerd aan Min. rambang, weifelen, onzeker, wankelmoedig, zijn.

rob(h)aya, 139, hier: collega. Vgl. K. B. W. I, 815 en het latere gebruik; vgl. p. 162, ond.

rangga, 136, waardigheidsbekleeder.

kanuruhan, 123, 131, 132, 135, 136, 137, een waardigheidsbekleeder. kěrět, pangěrět, p. 122, dwarsbalk; zie ook Bijdr. 88, p. 487.

kartala, kakarttala(n), 116, droevige toestand? Jb., p. 117, vgl. K. B.

W. II, 84 ; ondeugend(heid) (Poerb.). Is v. d. Tuuk's etymologie (uit karatala) juist?

krěpaṇu, 144, van mpu Bharada, heilige (Poerb.). Zonder twijfel samenhang met Skt. kṛpana, ,ellendig, arm”.

karamyan, 120, klimop (Poerb.).

karang, 124, woonstede, vgl. N. J. pakarangan en Soend. karang,

erf (met of zonder huis).

kakajar, 127, n. v. 'n plant. Vgl. Jb. s. v. kajar.

kusa, kuça (?), ma-, 127 (een lijk); a-ri çawa, 115. Vgl. p. 116;

117 akuçeng tunwan kinuça (subj. een lijk), 127.

koçali, 141, 144, gezegd van mpu Bharada, \pm heilige.

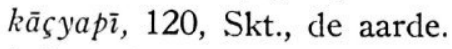

kalang, kalangan, 141, ommuring.

kalěngka, 122, 123, 129, 131, Skt. kalanika; vgl. Rām. 11, 63 ; Bmụ.

Pur. p. 48, 10.

kamahyangan, 130, kamayangan, 142.

kamanak, 119, 120, e. s. v. muz. instr. Vgl. G.-R., I, 533.

kabasang, - in -, 121, wat precies? 
dihin, 126, 128, 129, 137, 141, 142, eerst, vooruit.

duhun, ḍumuhun, 129.

duhkha-nastāpa, 144.

dirya, kadiryya, 138 , voor driya, = tinghal, mata, panon; dus: gezien.

drěmba, 132, bedrog (Poerb.). Aan N. J. drĕmba is wsl. niet ts

denken. Vgl. K. B. W. II, 426. Wsl. Skt. dambha.

dalu, kadalwan, 129, zeer, bovenmate.

děpa, duměpa-ḍĕpa, 120, met uitgestrekte armen.

depun, 128.

dyaya, 145, vgl. K. B. W. III, 545, gezegd van mpu Bharada. Uit

Skt. jaya?

dangka, 131, tempel (Poerb.).

těhěr, něhĕr, 122; 123, terstond daarop (iets doen).

tuhur, katuhur, 124, h.l. beleefd verzoeken mee te gaan; meenemen. tan wruh, katanwruhan, 123, 124, 128, onbekend.

tanuja, 135, Skt., zoon. Ontbreekt in K. B. W.

tari, tumari, 137; patari, 137, raadplegen. Vgl. N. J. en Soend.

tosi(?), 143, afstammeling, zoon; of van tos?, vgl. K. B. W. II, 669.

tolih, atolih, 135, atoliha, 135, a. sireng kaḍatwan.

tapi, 134, korte vorm (vgl. Soend.), Skt. tathāpi (athāpi).

tuju, katuju, 145, was bestemd voor.

tayan, 127, 135, kleedingstukken (Poerb.).

tampo, 124, rum (Poerb.). Vgl. Jb., s.v. en Nāg. 90, 3; = N. J. tape

(v. d. Tuuk).

tumĕnggung, 135, 136, een waardigheidsbekleeder.

sihl, kasihsihana, 125.

sandeya, $126,=$ sandeha.

santun, sasantun, 133, zie: sasari.

çūntātma, 144, gezegd van mpu Bharada. Skt. çānta + ātman.

sari, sasari, 132, zie onder sari I in K. B. W. III, 52.

surud, a-a, 139, 142; asurud hayu, 130, 131, 133.

srěbat-budur, 124. Over srěbat vgl. men K. B. W. III, 100; over budur, IV, 924.

sudi, kasudenana, 124.

sĕdĕp, tekst: sĕḍĕpi, sinĕḍĕpan, 133, 134 ; zie K. B. W. III, 159, s.v. sěděp.

setra, 127 , h. 1. veld, afgezonderd terrein, waar lijken neergelegd worden. Skt. kșetra, veld; terrein; stuk land. Vgl. T. P., p. 112: çetragamana.

çişya, kaçisya, 128. 
sazuala, 125, sawalanya, ,uit openhartigheid” (Poerb.).

sazuala-brahmacāari, 134, ,ruzie-brahmacāri” (Poerb.), ?; K. B. W. III, 221.

suwung, 122, 126, verlaten, onbewoond, als N. J.

silih, pinasilih, 141, ,kreeg dezelfde voorwerpen” (Poerb.). Misschien eerder te vergelijken met B. Y. 36, 9; zie echter abhușaṇa in het voorafgaande. Vgl. ook K. B. W. III, 239, b., r. $1-8$.

sapa, sumape, $\left({ }^{\circ} \mathrm{a}\right.$ i), 124 , vgl. Mal. měnjapa, iemand toespreken en vragen wie hij is.

sampun, vetat., 140 .

samyak, 119, ,werden rumoerig” (Poerb.), m.i. onjuist. Het woord zal het Skt. samyak, neutr. zijn, waarvan beteekenissen zijn: ,,vereenigd, op één punt gericht”, ,,juist, op de behoorlijke wijze, overeenkomstig de waarheid". In verband met de volgende woorden zou men aan laatstgenoemde beteekenis de voorkeur kunnen geven: ,bevestigen”, desnoods ,,eens zijn met”.

sangřt, 129, hevig, erg; den asangět, 129.

sungga, sanggan, 13.3, iets om te stutten, dragen, steun; Poerb. hier: schaal.

whakawarahan, 132; ?

w'anapastra (sic), 134, Skt. vānaprastha.

w'àcita, - nĕn, 141, 142, 145, er worde gesproken van. Bij Skt. vācayati, o.a. berichten.

wer, wera, 126, vgl. N. J., lang, uitgestrekt; babbelachtig (zoo hier). wire, wire 2 , 122, zie K. B. W. III, 470.

wiryakrta, 136, ,nadat hij zijn waardigheid verkregen had" (Poerb.),

m.i. liever ,op wirya ingesteld, geneigd tot w., blijk gevend van w.", waarbij men wellicht K. B. W. III, 490 wīrya (3e) : suka moet vergelijken.

z'akṣa, san mahā wakṣa, 135, gezegd van mpu Bharāḍa. Te lezen: mahāwakṣa, zie aldaar.

wekșa, 134, haywa tan gama-gamanta wekșa, handel niet zonder grond (?); zoo Poerb. M.i. voor awekșā, Skt. attentie, voorzorg, bezorgdheid, Rücksicht. Zie ook 143.

wadul, wadul'an, 143, kwaadsprekerij, leugenachtige praat over anderen, klikken.

watara, awatara, 122, ongeveer.

z'asi, angawasi, 130, 131 ; vgl. Pigeaud, Tantu P., Bladw., s.v. z'ascitta, 135; in de vertaling verwaarloosd. Blijkens K. B. W. III, 545 , is het een aanduiding voor mpu Bradah; zoo ook hier. Men D1. 90. 
zou kunnen denken aan een verbastering van Skt. vasitva, het eigen-heer zijn (vgl. Jb., s.v.). Het woord komt in het Skt. wel voor als: de bovennatuurlijke kracht om alles aan $z$ 'n wil te onderwerpen en als zelfbeheersching. - Ook p. 137, 140, 142. 143.

weçma, paweçma, 125. koopsom bij een huwelijk, = panomah, vgl.

K. B. W.. III, 556.

a'az'al, 129, (2 ×), sang mahā wawal, de groote heilige (Poerb.). a'ac'ala, 119, viersprong (Poerb.).

ailasa, 135, genegenheid, gunst, enz. Vgl. Bijdr., 89. p. 89.

a'ajendra, 141, 142, voortreffelijke legerschaar. Skt. vraja (hier met

verlies van (le $r$ ), schare, troep + inclra, beste in $z$ 'n soort.

a'ayo, 132; sa-. 145, alle bezittingen (Poerb.).

a'oy'a, 122, 124, 131. = wwaya, vgl. K. B. W. III, 566. Vgl ook hoya, enz.

wiyang, 125. 126, = II wihang. K. B. W. III, 450. Vgl. 122, miyang; gaan; heengaan.

wǒgil, amrĕgil. 123, 135. 138, tịjdelijk z’n intrek nemen; K. B. W. III, 620.

a'ingang, mawingang², 135. Beteekenis onzeker: paḍang maw. 2. volkomen helder (Poerb.).

landuh, 118, makalaṇduha(n). 122, tot rust, voorspoed, welvaart Vgl. K. B. W. III, 651 (.,rustig”').

landuh, 136, van regen: \pm in behoorlijke hoeveelheid vallende; vgl. K. B. W. III, 651.

lirik, lumirik, 129, vgl. N. J.

la'i ( ¿). malwi, 140, teruggaan.

lčlčp, kalělěp, 139. 140, onder water geraakt.

lěpih, lěpihan, 120, zie K. B. W. III, 739.

linggih, anglinggihi çàsana, 136: N. J. ngloenggoehi, nakomen, zich houden aan.

pundut, pupundutan, 124, opgediende gerechten. Vgl. Sònd. pamoepoendoet(an). spec. van spijzen: wat iemand gebracht wordt; moepoendoetan, iemand te eten brengen; poepoendoet, bedienden bij een feestmaaltijd enz., die de spijzen brengen. Zie ook p. 135, r. 12.

panť́nb(h)aya, 138, 139, 140, .,broeder”, collega. Het tweede deel is m.i. identiek met Min. bayŏ, leeftijd, ouderdom. Mal. baja, ..slag”. sěbaja, van hetzelfde slag. van clenzelfclen leeftijd. Heeft 
pantěn te maken met Mal. sĕ-pantoen, enz.? Zie ook K. B. W. IV, 254 en 120, a, r. 10 vlgg. Dit - baja, Mal. - baja < Skt. vayah, jeugdige leeftijd, leeftijd, (Altersstufe, Lebensjahre), dat ook > Jav. wajah, leeftijd. Ook in kabayan (vgl. in het Agastyap.: strī kabayan ikan lěwas rin rah). Onafhankelijk van Aichele (Zeitschr. f. Eing. Spr. 21, 3, zie Djåwå 11, 147 vlgg.) ben ik tot déze etymologie van $k$. gekomen. Misschien rechtstreeks verband: Skt. ,,jeugdige leeftijd” — Soend. Uilenspiegel?? (Vgl. Jav. wajah = poetoe?). Bij Mal. Ken Bajan verg. Bal. wajahan, wajan, cuder, 't eerste of oudste kind. (Van Eck). paran, 128, wong paran, wat voor personen. prana-suka, 122, vroolijk (Poerb.), Skt. prāṇa, adem, levensadem, + Skt. sukha, gelukkig. Hier kan men prāṇa als „hart” opvatten, verg. Pararaton 12, 21, alwaar concreet.

prānopaṇdya, (zoo te lezen?), 145, gezegd van mpu Bharāḍa.

prānaja, 143, zoon, Skt.

pereret, 132, 141, trompet.

prapa, 127, prapa yan, indien (Poerb.).

prabhangkara, 117, = prabhākara, de zon. Vgl. Par. 15, 21.

patra, 125, 126, S. pattra, o.a. beschreven blad, - document, h. 1. boek. pěṭet, pẹte-pěțetan, 118, tuinplanten (Poerb.). Vgl. Soend. pětetan, jonge plant(en), uit zaad voortgekomen.

pasuk, pasuk wětu, - ning bhuwana, 115; - ning lumukat, 129, nin jagat, 134, - nin rat, 135 . Vgl. K. B. W. III, 532 pasuk wĕtu: pati hurip.

pusad(h)i, 141, troonzetel (?). Zie Jb., 377, s. v. pusadi. Verg. ook Kern, V. G. VIII, p. 62, n. 1; p. 97, n. 2; Poerbatjaraka, Bijdr. Kon. Inst., 80, p. 249.

pasthan, 134, ,blad” (Poerb.). Etymologie en beteekenis staan m.i. niet voldoende vast. Misschien, vergeleken met p. 133, r. 22, in verband te brengen met het $\mathrm{K}$. B. W. IV, 210 besproken pastha.

puspa, bloemen bij het offer gebezigd, 133, in ruimeren zin gebruikt. palatra, 122, sterven, $=$ paratra.

palisir, 141, zie ook Jb., p. 350. Vgl. N. J. aangezette zoom, garneersel.

Ook Soend. ,rand met franje" enz.

palib(h)aya, 138, 139, collega, ,broeder”, 138, zie pantěnbhaya. pepeka, 121, 128, 131, onachtzaam.

pajang, pajajangan, 133, staatsiezaal, feestgebouw (zoo Poerb.); vgl. 
N. J. padjangan, gedrapeerd vertrek; staatsiebed; kobongan. Zie ook 141.

piñcul, mpiñcul-piñcul, 122, vgl. K. B. W. IV, 296; pancal? pangkas, papangkas, 115 , zie K. B. W. IV, 322 (Jb., p. 326, onjuist).

Aanduiding van een zekeren leeftijd. jiněm, kajinĕman, 123, door den slaap overvallen. jīwātma, 127, 129, 130, 131, gebruikt van Bharāọa. Door Jb., Wdl., s. v. vertaald met ,liefje”, hierbij volgt hij K. B. W., IV, 387. Skt. jīvātman, ,die lebende, individuelle Seele” (P. W.), ,individuated spirit" is ,a synthesis of spirit and cognitive internal organ" (Wilson-Hall, Vishṇu Pur. IV, 253). Hier wordt het woord m. i. gebruikt voor ,heilige, heilige man”.

jīwātmaka, 130, ,heilige” (Poerb.). Vgl. jīwātma; ,wiens natuur het leven, levensprincipe, de individueele ziel is".

jaba-kuta, 132, andere schakeering in gebruik dan K. B. W. IV, 431. yajñābhyāsa, 116, S. yajña + abhyāsa. -- ma-, 117.

yaȳ̧̧̄arī, 131, gemalin.

mahā̧̧anta, 117, 123, 126, 132, 134, 135, 137, e.a., Skt. (?), de heilige. mahāsāttruika, 142, edel. Vgl. R. Schmidt, Nachtr. P. W., s.v.: = prasannatāyuktatva.

mahäwakșas, 135, d.w.z. mpu Bharada, Skt., een groote, breede, borst bezittend, epitheton van Çiva.

manih, 129, 130, = muwah.

manira, 140, pron. 1e pers.

mantyanta, $127,141=$ antyanta, atyanta.

mārana of marana, kamaranan, 122, 123, 126, 127. Skt. marana, de

dood; of, waarschijnlijker, Skt. māraṇa, ,eine die Vernichtung

eines Feindes bezweckende Zauberceremonie" (P. W.).

mrĕdu, 116, 118, 123, 126, 128, 133, 135, e.a., \pm de zachtmoedige, goedaardige, gebezigd voor mpu Bharada.

mokṣa, 123, verdwịnen.

mottama, nișta-madyamottama, 133, Skt. n., madyama, uttama. In mijn Glossarium op het Bmḍ. Pur. (editie, p. 366) heb ik mottama trachten te verklaren. Het meest waarschijnlijk lijkt mij thans, dat het uit deze en dergelijke uitdrukkingen is gevormd, door verkeerde splitsing: madhya, mottama. In onzen tekst volgt echter: madya, uttama.

mwas, tan amwas, 131, 132, niet lang daarna.

mala, in: mala pataka, 129. Vgl. Mal. mala pataka, en K. B. W. IV, 581. Skt. mala bet. vuil, ook moreel, dan \pm pāpa. Vgl. even 
verder de uitdrukking papa pataka, die ook elders voorkomt (zie Jb., p. 340).

mūlya, Skt., kinamulen, 133, geëerd worden.

mpungku, 122, vg1. K. B. W. IV, 319. Men zie ook Bmḍ. Pur. p. 84, $24 ; 25$.

manguntur, 122, 132, gehoorzaal (Poerb.); vgl. echter K. B. W. III, 627 , onder wanguntur.

grčhasthana, grĕhastana, 134, vgl. Skt. grhastha. Niet in K. B. W.

Hiervan agrĕhasthana, 134.

groda, 129, 136, waringin-boom, < nyagrodha.

guruloka, 122; te lezen: guru loka. Vgl. ook pp. 123, 141.

gaḍing, anggagaḍing, 143, ,regelen” (Poerb.).

goșthī, goștinĕn, 145, vertellen.

gangsal, 118, 120, ter hand nemen.

bahung, am -, 122, 127, h.l. huilen (v. honden), vgl. N. J.

brahmacārika, 134, levenswijze van een brahmacārin, = brahmacarya. brětya, 119, Skt. bhrtya; dienaar.

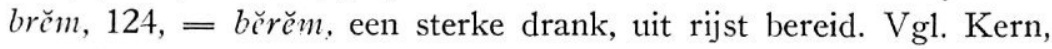

V. G. VIII, 108, n. 5.

bramila, $135(3 \times), 142$, door K. B. W. IV, 897, vermeld; ,,vorst” (Poerb.).

buḍu, vgl. onder: srěbat.

basah, babasahan, 124 , = basahan.

bilih, 126, wellicht, het zal wel.... zijn.

bilala, 138; vgl. K. B. W. IV, 994.

bhujangga, 125, h. 1. student; vgl. Bijdr. 89, p. 257. Vgl. p. 136, 141.

Een merkwaardige plaats voor bhujangga is de Mal. Hik. Radja

Moeda, ed. Winstedt, p. 68: těrlalu elok mějĕlis sikap baginda,

laksana indĕra dari kěyangan sipat-nya ěnum bujangga muda wangsa.

bcya, 132, onkosten ; < byaya.

byasu, 121, doode, Skt. vyasu.

bage, pambage, < Skt. bhāgya, verwelkoming, 126, e.a.

nguni, makanguni, 125, 141, en daarbij, bovendien. 
